\title{
Eye Tracking in Measuring the Relation of Anaphor Processing, Reading Fluency and Working Memory (WM) Capacity among University Students
}

\author{
Or-Kan Soh, Hazita Azman*, Shamita Chanthe rasarathy Naido \\ Faculty of Social Sciences \& Humanities, School of Language Studies \& Linguistics, \\ Universiti Kebangsaan Malaysia (UKM), Malaysia
}

Received February 12, 2020; Revised February 28, 2020; Accepted March 12, 2020

Copyright $\odot 2020$ by authors, all rights reserved. Authors agree that this article remains permanently open access under the terms of the Creative Commons Attribution License 4.0 International License

\begin{abstract}
This paper aimed at investigating (i) eye movement behaviour as indication of reading fluency during anaphor processing of young adults; (ii) and the relation between eye movement behaviours and Working Memory (WM) among young adults. This experiment used eye-tracking device to study the eye movements and Auditory Working Memory subtest to measure WM capacity. Tobii Eye-tracker was used to measure the movements of eyes for the participants. The results showed that young adults have similar eye movement behaviours, which were inverse typicality effect, as children. However, the score of their WC was similar to past studies whereby a larger WC capacity indicates better accessibility of resources and thus faster resolution of anaphors and antecedents. These findings were analy zed to determine the implications on the research development of eye-tracking towards students' reading fluency during anaphor processing and its relation to working memory.
\end{abstract}

Keywords Eye-Tracking, Anaphor Processing, Reading, Working Memory

\section{Introduction}

Past empirical studies have associated the relationships between reading fluency, anaphor processing and Working Memory (WM) through eye-tracking. Joseph, Bremner, Liversedge and Nation (2015) revealed that the magnitude and time course of children during anaphoric processing was seen to be greatly affected by WM capacity. One important finding from the study was in the antecedent region whereby the interactions among reading fluency, WM and typicality of the anaphor resolution revealed a difference in time course for those with high and low WM capacity. On the other hand, Garrod and Sanford (1977) in a study stated that adults exhibited shorter reading times when the antecedent was typical and presented longer first-pass reading times when anaphors were further from their antecedents. In addition, a large difference was observed due to individual differences in the WM capacity which affect reading fluency in adults (Carpenter, Miyake, \& Just, 1994; Dane man \& Carpenter, 1980; Mihat, Azman \& Soh, 2018; Hasrul, Hazita \& Azizah, 2018; Philip, Tan \& Jandar, 2019) and in children (Cain, Oakhill, \& Bryant, 2004; Pimperton \& Nation, 2010).

Reading fluency is the ability to read accurately and smoothly through recognition of individual words and then the integration of the meaning of words (Gernsbacher, 1990; Johnson \& Laird, 1983; Van Dijk, Kintsch, \& Van Dijk, 1983) as well as the ability to associate between current and previous information, such as in anaphor processing (Garrod, O'Brien, Morris, \& Rayner, 1990; Garrod \& Terras, 2000). McDonald (1995) described anaphor processing as the process of relating an antecedent to its anaphor. Antecedent (e.g. Mary) is usually a noun phrase which is mentioned earlier and provides the interpretation for a second expression, the anaphor (e.g. she). During anaphor processing, readers have to determine the potential antecedent in the preceding text and then deduce the relationship between the antecedent and the anaphor (Garrod \& Terras, 2000) which indicates a high demand of underlying complex cognitive skills and resource, specifically WM. WM as stated by Cowan (2010), "is the small amount of information stored in a readily accessible state in order to perform any cognitive tasks (p.447)" which can be used to reason out limitations in processing capacity (Leonard, Weis mer, Miller, Francis, Tomblin, \& Kail, 2007) and has captured the interest of 
researchers to establish its link to eye movement behaviours.

There were a considerable amount of studies researching on eye movements, anaphor processing and WM but majority have not combined all the elements together. In addition, there is a scarce of existing studies in this context among young adults. Hence, this study aims at examining anaphor processing, reading fluency and WM capacity among young adults by referring to the framework of Joseph, Bremner, Liversegde and Nation (2015) and incorporating eye movements. This study focused on:

i). eye movement behaviour as the indication of reading fluency during anaphor processing of young adults.

ii). relationships between eye movement behaviour and WM among young adults.

\section{Literature Review}

\subsection{Eye Movement Behaviour as the Indication of Reading Fluency during Anaphor Processing of Young Adults}

The typicality of an antecedent to its anaphor affects reading fluency which can be observed through eye movement behaviours, in terms of fixation durations. Results from previous studies among adult readers (Rosch, Mervis, Gray, Johnsen \& Boyes-Braem, 1976; Mc Koon \& Ratcliff, 1980; Duffy \& Rayner, 1990; Soh, 2017; Sarah Yusri \& Soh, 2019; Soh, Hazita, Noremy \& Shamita; 2020) implied that reading fluency was disrupted when the typicality of an antecedent was reduced and thus lengthened reading times as fixation durations increased. One of the study conducted by McKoon and Ratcliff (1980) revealed that shorter fixation duration of the antecedent was observed when the anaphor was directly repeated or explicit; whereas Duffy and Rayner (1990) found that longer fixation durations denoting longer processing time occurred when the antecedent of a category name anaphor (e.g. bird) had a low typicality of the category (e.g. goose) as compared to a high typicality member (e.g. robin). It is presumed that repeating of nouns and antecedents with high typicality provided greater sematic overlap, therefore reduced fixation durations and increas ed reading fluency in anaphor processing.

A study by Joseph, Bremner, Liversedge and Nation (2015) investigated on the effects of typicality on eye movements among children and observed effects of typicality relatively early during anaphoric processing, for instance, on the anaphor itself. They found no reliable effects of typicality in eye movement behaviours, such as first fixation durations, gaze durations, go past times or total reading times. However, they found effects of typicality during regression on the anaphor regions to re-read previous portions of the text. To specify, frequency of regression on the anaphor region was higher when the antecedent was typical than atypical. The result was inconsistent to the hypothes is made and contrary to the eye movement behaviour of adults, showing an inverse typicality effect. The findings can be explained by referring to the view of Garrod and Terras (2000) where they stated that the inverse typicality effects reflected children's early anaphoric processing, in which children used bottom-up, context-blind lexical cues to lin $\mathrm{k}$ the anaphor to the typical antecedent but not the atypical antecedent; and the closer sematic overlap of typical antecedent activated the me mory, hence, the inverse effect was justifiable as children, unlike adults, did not process atypical antecedent as it was not being activated. In addition, regressions on antecedent regions were slightly higher when the nouns were atypical members of the semantic category. This was in line with the prediction and consistent with the eye movement behaviours demonstrated by adult readers. Therefore, the purpose of this research is to investigate on the effects of reading fluency during anaphor processing by studying the eye movement behaviours of young adults and compare whether their eye movements portray similarity to children or adult readers.

\subsection{Relationships between Eye Movement Behaviours and WM among Young Adults}

In the past decades, previous researchers had highlighted the fact that eye-tracking had been used intensively as the method to study the sentence-level online processing based on the assumption that cognitive processes correlated with eye movement patterns during reading tasks which provided details such as fixation duration, gaze duration, first pass, and second pass (Just and Carpenter 1980; Pollatsek, Juhasz, Reichle, Machacek, \& Rayner, 2008). They believed that eye-tracking delivered an online measure of the mental operations during reading processing. Just and Carpenter (1992) pointed out that WM capacity has the potential to provide adequate and accurate explanations of individual variations in language comprehension and processing efficiency during reading tasks. In reading tasks, WM capacity is highly influential whereby it must be allocated to the various processes involved in activating lexical representations and integrating them into developing syntactic and discourse representations (Caplan \& Waters, 1990, 1999; MacDonald \& Christiansen, 2002; Soh, Hazita \& Ho, 2020), such as anaphoric processing. It is presumed that large WM capacities increased the ability of individuals to execute more processes in a given period of time and thus shorter fixation durations. For example, Joseph, Bremner, Liversedge and Nation (2015) examined on the relation of semantic typicality during anaphor processing through eye movements with individual differences in working memory capacity and reading comprehension skills. They mentioned that limitations in verbal WM is one of the reasond of poor anaphoric processing during reading. 
Furthermore, children with good vocabulary knowledge were expected to access words more efficiently which allowed more resources for comprehension processes and present shorter fixations and reading times which indicated better reading fluency (Perfetti, 2007; Soh, 2016). Thus, they were able to process an atypical antecedent faster, and thus resulting in an earlier typicality effect. In contrast, studies (Kuperman \& Van Dyke, 2011; Schroeder, 2011) on adolescents and adults demonstrated longer fixations and reading times during processing of anaphors with atypical antecedents. These findings raised a question among researchers whether the longer fixations and reading times in individuals with larger WM capacity could be the fact that they are more purposeful readers, thus allowing themselves more time to process text elements that are difficult. Thus, this research will investigate on the relation between eye movement patterns and WM among young adults and compare the findings with the previous studies to establish the re lationship between WM capacity and eye movements of young adults.

\section{Materials and Methods}

\subsection{Participants}

Table 1. Distribution of Particpants' Demography

\begin{tabular}{|c|c|c|c|c|}
\hline Gender & Malay & Bidayuh & Kelabit & Total \\
\hline Female & 10 & 10 & 10 & 30 \\
\hline
\end{tabular}

Thirty young adults participated voluntarily in this eye-tracking study. They were females who majored in
English Language Studies in The National University of Malaysia (UKM), which were of different races - Bidayuh, Kelabit and Malay. The age range of the participants are from 20 to 21 years old. Table 1 showed the distributions of participants. All of the participants had no prior exposure to eye-tracking research.

\subsection{Instruments}

The stimuli used were comprised of sixteen sets of short texts in English which were adapted from journal articles to maintain the reliability and validity of the experiment. The texts had an average of 3 to 5 sentences each. Each text had two versions presented in the same slide side-by-side. The first text had a more familiar antecedent (e.g. truck) while the other had fewer typical (e.g. crane). The typical and atypical antecedents did not differ in length. Both versions of texts within the same context had the same anaphor (e.g. truck). The anaphor and antecedents were the area of interest of the texts.

The anaphor regions are underlined and the antecedent regions are italicized.

Participants' eye movements were recorded using a Tobii X120 non-intrusive eye-tracker with $120 \mathrm{~Hz}$ sample rate. The apparatus was chosen for its features as it has (i) the flexibility in allowing slight head movements; (ii) the ability to carry out experiments for a long period of time without causing tiredness of the eyes; and (iii) high sensitivity in tracking and detection of word-to-word eye movements. The participants were not required to scroll the page as the texts were fixed to fit the whole screen. The participants had to signal the experimenter to proceed to the next slide.

Table 2. Example of stimuli

\begin{tabular}{|c|c|}
\hline Typical condition & typical Condition \\
\hline $\begin{array}{l}\text { It had been a long day. The builders were exhausted. Eventually a } \\
\text { truck arrived to help. They needed the vehicle because the load } \\
\text { was so heavy. At last they could start work on the building. }\end{array}$ & $\begin{array}{l}\text { It had been a long day. The builders were exhausted. Eventually a } \\
\text { crane arrived to help. They needed the vehicle because the load was } \\
\text { so heavy. At last they could start work on the building. }\end{array}$ \\
\hline $\begin{array}{l}\text { It was a sunny afternoon. Judy was walking home from school, } \\
\text { daydreaming about herself. She crossed the busy street at the } \\
\text { light. She stopped to watch the traffic while she gathered her } \\
\text { thoughts. She had just decided she was going to be a doctor when } \\
\text { she grew up. The profession seemed to be an exciting one. She } \\
\text { knew she would have to work hard at school. }\end{array}$ & $\begin{array}{l}\text { It was a sunny afternoon. Judy was walking home from school, } \\
\text { daydreaming about herself. She crossed the busy street at the light. } \\
\text { She stopped to watch the traffic while she gathered her thoughts. } \\
\text { She had just decided she was going to be a meteorologist when she } \\
\text { grew up. The profession seemed to be an exciting one. She knew } \\
\text { she would have to work hard at school. }\end{array}$ \\
\hline $\begin{array}{l}\text { Adam had been driving around the city for thirty-five minutes. } \\
\text { He'd been trying to find the train station but it was nowhere in } \\
\text { sight. Although the map to the station was old, Adam still couldn't } \\
\text { understand why he was unable to find it. He stopped and asked for } \\
\text { directions and realized that he was in the wrong town. }\end{array}$ & $\begin{array}{l}\text { Adam had been driving around the city for thirty-five minutes. He'd } \\
\text { been trying to find the gas station but it was nowhere in sight. } \\
\text { Although the map to the station was old, Adam still couldn't } \\
\text { understand why he was unable to find it. He stopped and asked for } \\
\text { directions and realized that he was in the wrong town. }\end{array}$ \\
\hline
\end{tabular}




\subsection{Procedures}

A trial experiment were conducted before the actual experiment to determine the best condition to present the stimuli in terms of the font size, text configurations, average time taken to read each text and the sequence. The trial was conducted almost similarly to the actual experiment. The participants for the trial experiment were not involved in the actual experiment. At the end of the trial, the participants were intervie wed to find out the best sets of condition for the stimuli.

All the participants were gathered for a short briefing before the actual experiment was carried out. Then, they were called individually into the experiment room and underwent a standard 9-point calibration process before proceeding to the real experiment. Each participants took an average of 15-20 minutes to complete the whole experiment. After the experiment, a standardized test was adapted and carried out to measure the participants' WM capacity using the Auditory Working Memory subtest from the Woodcock Johnson Test of Cognitive Abilities. The experimenter read out a mixed series of words and digits. The participants then rearrange them by first saying the words in order and then the numbers. The task was administered and scored according to manual instructions.

\section{Results}

This experiment investigated on the eye movement behaviour as indication of reading fluency during anaphor processing of young adults. Each text was divided into two regions of interest which are the anaphor region and the antecedent region. The eye movement measures that were calculated for the anaphor and antecedent regions were total fixation duration and visit count as shown in Table 3 and Table 4 below. The eye movement data was also analysed with the score for working memory capacity as in Table 5.

Table 3. Total fixation durations and visit count in the anaphor and antecedent regions

\begin{tabular}{|c|c|c|c|}
\hline Eye movement measure (s) & Region & Typical M (SD) & Atypical M (SD) \\
\hline Total fixation & Anaphor & $0.27(0.24)$ & $0.20(0.20)$ \\
\hline durations & Antecedent & $0.44(0.34)$ & $0.40(0.27)$ \\
\hline Visit count & Anaphor & $1.00(0.80)$ & $0.81(0.74)$ \\
\hline & Antecedent & $1.63(0.99)$ & $1.31(0.84)$ \\
\hline
\end{tabular}

Table 4. Participants score for Auditory Working Memory subtest and mean total fixation durations in the anaphor and antecedent regions

\begin{tabular}{|c|c|c|c|c|c|c|}
\hline \multirow{2}{*}{ Participant } & \multicolumn{2}{|c|}{ Auditory Working Memory } & \multicolumn{4}{|c|}{ Mean total fixation durations (s) } \\
\cline { 2 - 8 } & Score & $\begin{array}{c}\text { Age Equivalent } \\
\text { estimation }\end{array}$ & $\begin{array}{c}\text { Typical } \\
\text { Antecedent M }\end{array}$ & $\begin{array}{c}\text { Typical anaphor } \\
\text { M }\end{array}$ & $\begin{array}{c}\text { Atypical } \\
\text { antecedent M }\end{array}$ & $\begin{array}{c}\text { Atypical } \\
\text { anaphor M }\end{array}$ \\
\hline 1 & 24 & $13-7$ & 0.53 & 0.17 & 0.56 & 0.18 \\
\hline 2 & 29 & $>22$ & 0.32 & 0.24 & 0.19 & 0.19 \\
\hline 3 & 30 & $>22$ & 0.33 & 0.22 & 0.38 & 0.30 \\
\hline
\end{tabular}

Table 5. Participants score for Auditory Working Memory subtest and mean total fixation durations in the anaphor and antecedent region $\mathrm{s}$

\begin{tabular}{|c|c|c|c|c|c|c|}
\hline \multirow{2}{*}{ Participant } & \multicolumn{2}{|c|}{ Auditory Working Memory } & \multicolumn{4}{|c|}{ Mean total fixation durations (s) } \\
\cline { 2 - 8 } & Score & $\begin{array}{c}\text { Age Equivalent } \\
\text { estimation }\end{array}$ & $\begin{array}{c}\text { Typical } \\
\text { antecedent M }\end{array}$ & $\begin{array}{c}\text { Typical anaphor } \\
\text { M }\end{array}$ & $\begin{array}{c}\text { Atypical } \\
\text { antecedent M }\end{array}$ & $\begin{array}{c}\text { Atypical } \\
\text { anaphor M }\end{array}$ \\
\hline 1 & 24 & $13-7$ & 0.53 & 0.17 & 0.56 & 0.18 \\
\hline 2 & 29 & $>22$ & 0.32 & 0.24 & 0.19 & 0.19 \\
\hline 3 & 30 & $>22$ & 0.33 & 0.22 & 0.38 & 0.30 \\
\hline
\end{tabular}


Based on Table 3, it can be summarized that there is only a marginal difference between typical and atypical anaphor and antecedent regions in mean total fixation durations of the participants. The mean total fixation durations of the participants for both typical antecedents $(\mathrm{M}=0.27, \mathrm{SD}=0.24)$ and anaphors $(\mathrm{M}=0.44, \mathrm{SD}=0.34)$ regions are longer compared to atypical antecedents $(\mathrm{M}=0.40, \mathrm{SD}=0.27)$ and anaphors $(\mathrm{M}=0.20, \mathrm{SD}=0.20)$ regions and therefore, indicating lower reading fluency. Hence, it can be concluded that the participants did not show difficulty processing the atypical antecedents which is opposite to that predicted, whereby young adults will exhibit similar eye movement behaviour to adults by producing longer total fixation durations on atypical antecedents than typical antecedents. The data also summarized on the visit count in the anaphor and antecedent regions. The result indicate that the typical antecedents $(\mathrm{M}=1.63, \mathrm{SD}=0.99)$ and anaphors $(\mathrm{M}=1.00$, $\mathrm{SD}=0.80)$ had higher frequency than atypical antecedents $(\mathrm{M}=1.31, \mathrm{SD}=0.84)$ and anaphors $(\mathrm{M}=0.81, \mathrm{SD}=0.74)$. It can be presumed that the participants did not have much difficulty in processing the atypical antecedents than the typical antecedents.

\section{Discussion}

\subsection{Eye Movement Behaviour as the Indication of Reading Fluency during Anaphor Processing of Young Adults}

Overall, the data summarized that there is only a marginal difference between typical and atypical anaphor and antecedent regions in mean total fixation durations of the participants. The data demonstrated that the mean total fixation durations for both typical antecedents and anaphors regions are longer compared to atypical antecedents and anaphors regions and therefore, indicating lower reading fluency. The result opposed to the prediction made whereby atypical antecedents will produce longer total fixation durations due to low semantic overlap to its anaphor and disrupt reading fluency. In addition, it is also in contrast to previous studies made among adult readers (Rosch, Mervis, Gray, Johnsen \& Boyes-Braem, 1976; Mc Koon \& Ratcliff, 1980; Duffy \& Rayner, 1990; Duffy \& Rayner, 1990) which revealed that the eye movement behaviour of adult readers during anaphor processing is longer fixation durations when the antecedent has a low typicality of the anaphor category. However, the results from this experiment demonstrate inverse typicality effect which is consistent with findings from a study by Joseph, Bremner, Liversedge and Nation (2015) on anaphoric processing among children. They mentioned that the possibility of this could be due to the high demand of resource during processing of atypical antecedents which can also be a factor among the participants of this experiment. One other possible justification is that the data from this experiment showed that there is a considerable amount of word skipping on average in the text which contains atypical antecedents among the participants. Therefore, the total fixation durations of the antecedent regions will be directly influenced by the frequency of word skipping for that particular region. Next, the data also summarized on the visit count in the anaphor and antecedent regions by looking at the frequency of visit count of the area of interest. This particular metric was chosen instead due to the unavailability of regression data in the system. The visit duration count is similar to regression whereby it provides data on the number of visits made to that particular area of interest. The result indicate that the participants made more visit count for typical antecedents than atypical antecedents. This is consistent with the findings from Joseph, Bremner, Liversedge and Nation (2015) which stated that majority of the children had high frequency of regressions before successfully connecting the atypical antecedents to its anaphor as compared to typical antecedents. They explained that anaphoric processing among children is progressive whereby when the linking process is more difficult, as in the atypical condition, evidence of processing emerges later in reading which can be observed at the post-anaphor region. Therefore, further research can be done on the post-anaphor region to verify the eye movement behaviour of young adults to the behaviour of children and substantiate the findings of this experiment. Moreover, they stated that a higher frequency of regressions may denote an early bonding stage of anaphoric processing. Nevertheless, the participants may also produced lower frequency of visit counts for atypical antecedents because of their word skipping behaviour.

\subsection{Relationships between Eye Movement Behaviour and WM among Young Adults}

To summarize, participants with a larger WM capacity, indicated by higher score of auditory working memory subtest, has lower mean total fixation durations on both typical and atypical antecedents which also implies better reading fluency. The result which shows that participants with larger WM capacity process antecedents faster is consistent with the prediction made. It can be seen that participants 1 and 2 took shorter time to resolve the atypical antecedent to its anaphor as they have larger WM capacity. This means they have better resources and therefore are able to link antecedents to its anaphor in a shorter time. Thus, this support the theory (Perfetti, 2007) that individuals with larger WM capacity will be able to process an atypical antecedent faster. Individuals, both children and adult with better reading fluency and large WM capacity resolve the anaphors as soon as their eyes left the post-anaphor region which possibly could be due 
to fast anaphor-antecedent lin king with high WM capacity, broad vocabulary and strong semantic links within their lexicons. Nevertheless, the results from this experiment do not match the study by Joseph, Bremner, Liversedge and Nation (2015), where the results from the antecedent region show no reliable effects of typicality. Furthermore, the children with good reading fluency and smaller WM capacity demonstrated longer reading times on atypical than typical antecedents. They expressed that the children with smaller WM capacity may require more time to process the atypical anaphor completely. Hence, further study is necessary in order to form a firm conclusion on the relation between WM capacity and eye movement behaviour, particularly the total fixation durations, among young adults, given the limited size of sample of this experiment.

\section{Conclusions}

In conclusion, this experiment provided an insight on the eye movement behaviour of young adults during anaphor processing which implies the fluency of reading and also the relation between eye movements and WM capacity. Overall, the result show that the participants demonstrated inverse typicality effect whereby they have longer fixation durations on typical antecedents than atypical antecedents which resembles children's eye movement behaviour instead of adult readers. Besides, the participants with larger WM were able to process and link antecedents to its anaphor faster than those with smaller WM capacity due to larger resources.

\section{Limitations and Future Recommendations}

One of the limitations of this experiment is the population sample. A larger group of sample with diverse population background should be considered for future research. A larger data will aid in establishing the relation of eye movement behaviour during anaphor processing with reading fluency as well as WM capacity. Furthermore, a larger population sample will provide a more reliable and valid data as a reference for other future research. Next, the data from this experiment may be inaccurate due to human factor. For example, the word skipping behaviour observed among the participants do influence the result, especially on the eye movement behaviour - the total fixation durations of atypical antecedents. The participants may have skipped the texts with atypical antecedents as they were familiar with it. Therefore, future research may present the two texts in different slides. Other than that, the environment of the room was not suitable as one of the participants expressed after the experiment that their concentration was affected by the loud noise from the renovation work nearby. As for the data analysis, the eye-tracking system used lacked metrics such as regression and saccade, so in-depth analysis on the eye movement behaviour could not be done. Lastly, future research can implement the automated version of the Auditory Working Memory Test as it will produce better accuracy of data.

\section{Acknowledgements}

This research was supported by the research grant FRGS/1/2017/SSI01/UKM/01/

\section{REFERENCES}

[1] Philip, B., Tan, K. H. \& Jandar, W. A. (2019). Exploring Teacher Cognition in Malaysian ESL Classrooms. 3L: The Southeast Asian Journal of En glish Lan guage Studies, 25(4), $156-178$.

[2] Cain, K., Oakhill, J., \& Bry ant, P. (2004). Children's reading comprehension ability: Concurrent prediction by working memory, verbal ability, and component skills. Journal of Educational Psychology, 96(1), 31-42. doi:10.1037/0022-0663.96.1.31

[3] Caplan, D., \& Waters, G. S. (1990). Short-term memory and language comprehension: A critical review of the neurop sy chological literature.

[4] Caplan, D., \& Waters, G. S. (1999). Verbal working memory and sentence comprehension. Behavioral and brain Sciences, 22(1), 77-94.

[5] Carpenter, P. A., Miy ake, A., \& Just, M. A. (1994). Working memory constraints in comprehension: Evidence from individual differences, aphasia, and aging. In M. A. Gernsbacher (Ed.), Handbook of psycholinguistics (pp. 1075-1122). San Diego, CA: Academic Press.

[6] Cowan, N. (2010). Multiple concurrent thoughts: The meaning and developmental neuropsychology of working memory. Develop mental neurop sy chology, 35(5), 447-474.

[7] Daneman, M., \& Carpenter, P. A. (1980). Individual differences in working memory and reading. Journal of Verbal Learning and Verbal Behavior, 19, 450- 466. doi:10.1016/S0022-5371(80)90312-6

[8] Duffy, S.A., \& Rayner, K. (1990). Eye movements and anaphor resolution: Effects of antecedent typicality and distance. Language and Speech, 33, 103-119

[9] Garrod, S., \& Sanford, A. (1977). Interpreting anaphoric relations: The integration of semantic information while reading. Journal of Verbal Learning and Verbal Behavior, 16(1), 77-90. doi:10.1016/ S0022-5371(77)80009-1

[10] Garrod, S., O'Brien, E. J., Morris, R. K., \& Rayner, K. (1990). Elaborative inferencing as an active or passive process. Journal of Experimental Psychology: Learning, Memory, and Cognition, 16, 250-257. doi: 10.1037/02787393.16.2.250 
[11] Garrod, S., \& Terras, M. (2000). The contribution of lexical and situational knowledge to resolving discourse roles: Bonding and resolution. Journal of Memory and Lan guage, 42, 526-544. doi:10.1006/jmla.1999.2694

[12] Gernsbacher, M. A. (1990). Language comprehension as structure building. Hillsdale, NJ: Erlbaum.

[13] Hasrul, K., Hazita, A., Azizah, M., Z. (2018). Research Trend in the Practice of Differentiated Instruction. The Journal of Social Sciences Research, 4(12), 648-668. https://doi.org/10.32861/jssr.412.648.668

[14] Joseph, H. S., Bremner, G., Liversed ge, S. P., \& Nation, K. (2015). Working memory, reading ability and the effects of distance and typicality on anaphor resolution in children. Journal of Cognitive Psychology, 27(5), 622-639.

[15] Johnson-Laird, P. N. (1983). Mental models: Towards a cognitive science of lan guage, inference, and consciousness (6th ed.). Cambridge, M A: Harvard University Press.

[16] Just, M. A., \& Carpenter, P. A. (1980). A theory of reading: From eye fixations to comprehension. Psy chological review, 87(4), 329.

[17] Just, M. A., \& Carpenter, P. A. (1992). A capacity theory of comprehension: individual differences in working memory. Psy chological review, 99(1), 122.

[18] Leonard, L. B., Weismer, S. E., Miller, C. A., Francis, D. J., Tomblin, J. B., \& Kail, R. V. (2007). Speed of processing, working memory, and language impairment in children. Journal of speech, language, and hearing research, 50(2), 408-428. doi:10.1044/1092-4388(2007/029

[19] Kuperman, V., \& Van Dyke, J. A. (2011). Effects of individual differences in verbal skills on eye-movement patterns during sentence reading. Journal of Memory and Language, 65(1), 42-73. doi:10.1016/j.jml.2011.03.002

[20] MacDonald, M. C., \& Christiansen, M. H. (2002). Reassessing working memory: comment on Just and Carpenter (1992) and Waters and Caplan (1996).

[21] McDonald, J. L., \& MacWhinney, B. (1995). The time course of anaphor resolution: Effects of implicit verb causality and gender. Journal of Memory and Lan guage, 34(4), 543-566.

[22] McKoon, G., \& Ratcliff, R. (1980). The comprehension processes and memory structures involved in anaphoric reference. Journal of Verbal Learning and Verbal Behavior, 19, 668-692.

[23] Mihat, W., Azman, H. \& Soh, O.K. (2018). Bringing reading research in multilingual Nusantara into a new direction through eye-tracking. Journal of Nusantara Studies, 3(2), 107- 123. http://dx.doi.org/10.24200/jonus.vol3iss2pp 107 123

[24] Pimperton, H., \& Nation, K. (2010). Suppressing irrelevant information from working memory: Evidence for domain-specific deficits in poor comprehenders. Journal of Memory and Language, 62, 380-391. doi:10.1016/j.jml.20 10.02.005

[25] Perfetti, C. (2007). Reading ability: Lexical quality to comprehension. Scientific Studies of Reading, 11,357-383. doi:10.1080/10888430701530730
[26] Pollatsek, A., Juhasz, B. J., Reichle, E. D., Machacek, D., \& Rayner, K. (2008). Immediate and delayed effects of word frequency and word length on eye movements in reading: A reversed delayed effect of word length. Journal of Experimental Psychology: Human Perception and Performance, 34(3), 726.

[27] Rosch, E., Mervis, C.B., Gray, W.D., Johnsen, D.M., \& Boyes-Braem, P. (1976). Basic object s in natural categories. Cognitive Psychology, 9, 382-440.

[28] Sarah Yusri \& Or-Kan, Soh. (2019). Examining University Students' Reading Performances and Behaviors with the Use of Eye-Trackers. International Journal of Academic Research in Business and Social Sciences, 9(8), 114-123. DOI: 10.6007/IJARBSS/v9-i8/6221

[29] Schroeder, S. (2011). What readers have and do: Effects of students' verbal ability and reading time components on comprehension with and without text availability. Journal of Educational Psychology, 103, 877-896. doi: 10.1037/a0 023731

[30] Soh, O. K., Hazita, A., \& Ho, S. M. (2020). A Systematic Review on Bilingualism and Language Processing from 2015-2019. 3L: The Southeast Asian Journal of English Lan guage Studies, 26(1), 1 - 14. http://doi.org/10.17576/3 L-2020-2601-

[31] Soh, O. K., Hazita, A., Noremy, M. A., Shamita, C. N. (2020). A Review Of Research On The Relationships Between Reading Fluency And Eye Movements Among Students. International Journal of Psychosocial Rehabilitation, 24(4), 4424 - 4433. DOI: 10.37200/IJPR/V 24I4/PR201546

[32] Soh, O. K. (2016). Examining the reading behaviours and performances of sixth-graders for reading instruction: evidence from eye movements. Journal of e-Learning and Knowledge Society, 12(4), 63-79.

[33] Soh, Or-Kan. (2017). Processing academic science reading texts through context effects: Evidence from eye movements. EURASIA Journal of Mathematics, Science and Technology Education, 13(3), 771-790.

[34] Van Dijk, T. A., Kintsch, W., \& Van Dijk, T. A. (1983). Strategies of discourse comprehension. New York, NY: Academic Press. 